\title{
Sometimes hesitancy is justified
}

\author{
Gilbert Berdine MD
}

The article titled "Hesitancy" presents the argument in favor of vaccination. Lot and his wife failed to heed the warnings of Angels of the Lord and Lot's wife became a pillar of salt due to hesitancy. However, Dr. Anthony Fauci is not an Angel of the Lord, so we might want to carefully consider his advice before jumping into what is a novel gene therapy. Although "He who hesitates is lost" contains wisdom, so does the saying,

\section{Haste makes waste.}

With the passing of time, there are more concerns being raised about complications from the vaccine. Myocarditis in a previously healthy 20 -year-old is just as much a tragedy as a case of COVID-19. Different groups have different risks for COVID-19. A school age child is more likely to be killed by a lightning strike than from COVID-19. The balance of risk vs. benefit is much different for a young healthy person than an elderly person with co-morbid conditions.

I must disagree with the experts cited in Hesitancy that people who decline vaccination put the vaccinated at risk. If the vaccine works, everyone who is vaccinated is protected and has nothing to fear from anyone infected with COVID-19. The only way that unvaccinated people put the vaccinated at risk is if the vaccine selectively works only in those who decline to be vaccinated and fails to work in the vaccinated. This argument does not make sense. Either the vaccine works or it does not. Either way, the vaccinated have nothing to fear from those who decline; their fear should be directed at the effectiveness of the vaccine.
I also must disagree with experts, including Dr. William Schaffner, that the unvaccinated are responsible for the variants. The natural selective pressure favoring variants occurs as the number of susceptible hosts for the virus declines. This decline is hastened by vaccination, so one can argue that the vaccine creates the variants. The variants will emerge with or without vaccination due to natural immunity; vaccination only hastens the natural process.

With apologies to Hamlet,

To be vaccinated, or not to be vaccinated?

That is the question.

I submit there is no objectively correct answer to the question, but the correct decision depends on the subjective valuation of the risks and benefits, which can only be decided by each individual.

Article citation: Berdine G. Sometimes hesitancy is justified. The Southwest Respiratory and Critical Care Chronicles 2021;9(40):82

From: Department of Internal Medicine, Texas Tech University Health Sciences Center, Lubbock, Texas

Submitted: $7 / 15 / 2021$

Accepted: $7 / 16 / 2021$

Conflicts of interest: none

This work is licensed under a Creative Commons Attribution-ShareAlike 4.0 International License.
Corresponding author: Gilbert Berdine

Contact Information: Gilbert.Berdine@ttuhsc.edu DOI: 10.12746/swrccc.v9i40.907 